\section{EL RETO}

DE LA

\section{CONSTRUCCION}

\section{J. Martitegui Susunaga, Arquitecto OoO-1}

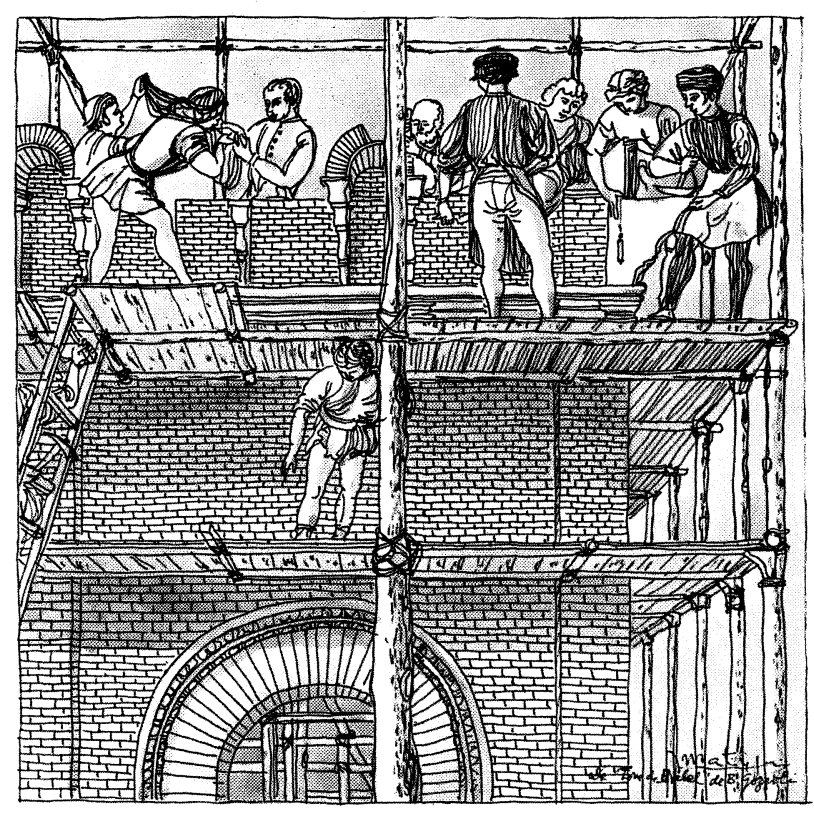

Actualmente se da un desfase genérico entre el sentido que nuestra dinámina social exigiría de la actividad de la Construcción y el sentido real de nuestra actuación práctica.

Tal desfase constituye un gravísimo perjuicio para la sociedad, ya que colabora acusadamente a la inflación, perjudica a la Industria y deteriora los intereses profesionales y económicos de los técnicos.

Puesto que las estructuras profesionales no han venido tomando conciencia de este problema y parecen incapaces de acometerlo y resolverlo resulta ineludible y urgente promover tal toma de conciencia.

\section{UNAS NOTAS PREV!AS DE CARACTER PERSONAL}

..."Yo no vengo, amigos, a concitar vuestras pasiones...

...No soy orador... sino, como todos sabéis, un hombre franco y sencillo... sin talento ni elocuencia, ni mérito, ni estilo, ni ademanes; ni dotado del poder de la oratoria, que enardece la sangre de los hombres. Hablo llanamente y no os digo, sino lo que todos conocéis: Os muestro las heridas del bondadoso César y les pido que ellas hablen por mí.l...

(W. Shakespeare. "Julio César»)
Es costumbre, al escribir sobre temas tècnicos, hacerlo con estilo impersonal, expresándose a manera de un observador ajeno al problema: escribir - como solemos decir- "asépticamente». Considero tal costumbre, no sólo inconsecuente con la naturaleza última de la técnica - que consiste en "creatividad" - sino especialmente nociva, hoy, para la propia técnica; ya que puede colaborar a la actitud de resignada apatía o dejación en que estamos cayendo, en contraste con la actitud activa y creadora que la técnica -en nuestro caso la técnica de la Construcción- exigiria de nosotros, en el nivel actual, supuesto que nos colocáramos a la altura de las circunstancias.

Voy a tratar en este artículo el desfase genérico que se da entre el sentido que el nivel actual exigiría de la actividad de la Construcción y el sentido real de nuestra actuación práctica, desfase que, afectando a las líneas fundamentales; de por sí, desvirtúa, minimiza o hace ineficaces aquellos esfuerzos y logros parciales que, en el mejor de los casos, pudieran llevarse a cabo (1). ¿Puede darse una empresa más atrayente, más digna de ser considerada y más adecuada para poner a prueba la capacidad de los técnicos, que acometer la resolución de una problemática -o al menos su diagnóstico y consideración- que condiciona todos y cada uno de los aspectos parciales de la Construcción? Y bajo el aspecto económico ¿Qué pérdida económica representará para el pais, anualmente, el hecho de que a causa de este desfase, se cumplimenten precariamente los requerimientos sociales; se desaproveche y frene la actividad de la Industria; se desvirtúe y desperdicie la formación de los técnicos; se ignoren, en alto grado, las posibilidades de las tecnologías y se dificulte o impida el encaje de los profesionales en la actividad?

Entiendo que el tema de este artículo está en perfecta concordancia con los objetivos que expresa el Comité de Redacción de "Informes de la Construcción» en el Editorial:

... «Perseguir un enfoque pluridisciplinar del fenómeno constructivo»... (en orden a)... "un avance de conocimientos en las áreas científicas y técnica de la Construcción».. (y especialmente)... «exponer las zonas comunes que existen entre la investigación y la práctica profesional»... etc.

Una vez puestas de manifiesto la amplitud y trascendencia del tema que voy a tratar, considero conveniente exponer cuáles son las razones que me llevan a tomar una postura comprometida abandonando la actitud aséptica o pasiva:

(1) Mis referencias y experiencias afectan, fundamentalmente, al Campo de la Edificación, pero dado el tratamiento genérico que aquí se considera, entiendo que, en sus grandes líneas, son aplicables al campo total de la Construcción. 
- Si se da, verdaderamente, la situación genérica de desfase a la que he hecho referencia, con la secuela consiguiente de perjuicios sociales, económicos y profesionales $-y$ no conozco a nadie que niegue este supuesto- ¡no sé quién pueda venir a diagnosticar esta situación, a interesarse por ella y a corregirla, si no somos nosotros mismos! Y si somos nosotros los llamados a diagnosticar y corregir ¿cómo podriamos contemplar la situación "asépticamente», como espectadores lejanos y ajenos, sin tomar parte, apasionadamente, en el empeño?

- A este argumento, que puede considerarse de orden general, debo añadir otros de orden particular: Desde hace muchos años vengo manteniendo en el ámbito de nuestros organismos profesionales (2) la exigencia ineludible de encarar y acometer nuestros problemas a la altura que las circunstancias exigen, so pena de pechar tarde o temprano con las consecuencias, y, naturalmente, la marcha de las cosas me viene dando la razón; paralelamente, el tiempo de mi dedicación a esta materia - al menos de unos 12 años - me ha proporcionado un bagaje de instrumentos y resultados que me permite hoy tratar aquellos problemas en el nivel de rigor que su naturaleza exige. Tengo pues la satisfacción de señalar que -en razón, no a mis méritos, sino al largo tiempo de estudio- aun cuando la exposición que ofrezco aquí es, necesariamente, muy esquemática, todas las manifestaciones que hago están fundadas en experiencias y resultados contrastables y en la mayor parte de los casos podrian ser exhaustivamente desarrolladas y justificadas, tanto en sus aspectos más especificos como en aquellos más generales. Sin embargo, aun cuando podría tratar este tema bajo un planteamiento coherente con los supuestos más genéricos de nuestra dinámica social -es decir, bajo un aspecto eminentemente científico (3) - en orden a la operatividad, he preferido ofrecerlo a través de una exposición muy asequible y práctica, que aun cuando reste altura teórica al planteamiento, le infunda un cierto carácter crítico y polémico del que tan necesitados estamos para sacudir la apatía en la que, según todos los sintomas, hemos caído. Se trata, en todo caso, de una actitud constructiva dirigida a procurar un empeño saludable, que no podemos, 0 , al menos, no debemos, soslayar. Aquí son aplicables aquellas palabras: ... «Si nosotros callamos... hablarán las piedras"...

Finalmente quiero expresar $\mathrm{mi}$ reconocimiento al Comité de Redacción de esta revista, por el hecho de proporcionarnos la ocasión de enfrentarnos, en

(2) Me refiero a los organismos profesionales de los arquitectos; y ello, ya, desde la década del 60 al 70 . el $n .^{\circ} 327$, primero de una nueva fase o singladura, con este tema, por una parte tan trascendente y por otra parte tan soslayado. Sean cuales fueren los juicios sobre los valores absolutos en los resultados obtenidos $-y$ en consideración, naturalmente, a los medios - es evidente que el Instituto Eduardo Torroja es el centro que -con muchomás eficazmente ha influido en la tecnificación de nuestra actividad. Sería muy deseable que ante el vacio que hoy se da en el campo de las líneas estratégicas -condicionantes- el Instituto se empeñase en la empresa de acometer este vacio; con lo cual se pondría en situación de cumplimentar eficazmente -entre otros - aquel último objetivo señalado en el Editorial: ...ufomentar lazos con la comunidad internacional cientifica y técnican...

(3) Que por otra parte no dejaría de estar en concordancia con los objetivos expuestos en el Editorial, principalmente con aquellos de «exponer las zonas comunes... entre la investigación y la práctica profesional»... y ufomentar lazos con la comunidad internacional científica».

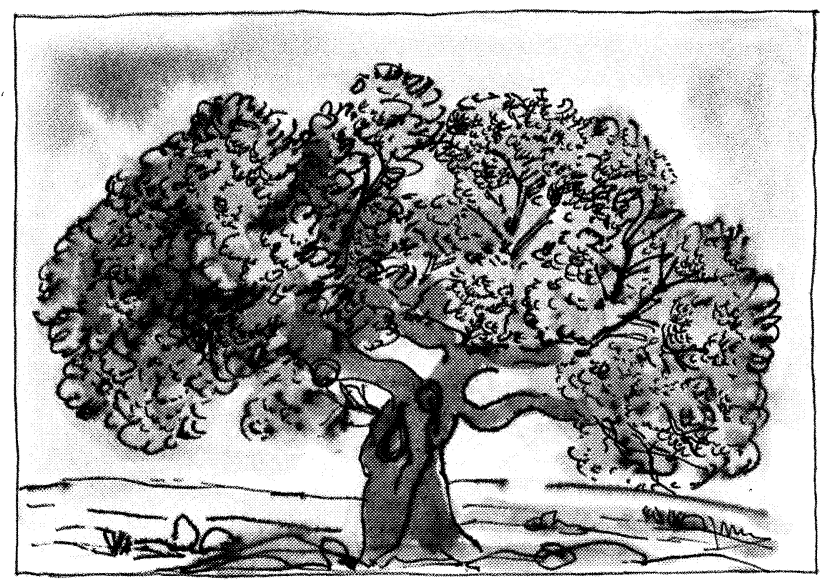

Se puede comprobar fácilmente que el organismo vegetal - tomemos como ejemplo un árbol - cumplimenta la definición de sistema - de Spranger - que se cita en el texto del articulo. En todo sistema al margen de la relación -concordancia de sentido - que liga la parte con el "todo propio", hay que considerar la relación - concordancia de sentido - del sistema con su entorno operativo (es decir, todo sistema es un subsistema) lo cual justifica y explica el significado del famoso teorema de Gödel.

\section{LA CONSTRUCCION EN EL CONTEXTO DE LA DINAMICA SOCIAL}

... "Las vulgares divisiones del Universo entre sujeto y objeto, mundo interior y mundo exterior, cuerpo y alma; no sirven, ya, más que para suscitar equívocos»... ... «Por primera vez en el curso de la historia, el hombre no encuentra ante sí más que a sí mismo, en el Universol...

\section{(W. Heisenbèrg. "Más allá de la Física»)}

Aun cuando, tal como he adelantado, mi intención es tratar directa y explícitamente de los problemas 
Informes de la Construcción/327

prácticos y condicionantes de la actividad de la Construcción y del camino adecuado para promover las correcciones pertinentes, tal objetivo aconseja, considerar la Construcción como un medio o instrumento -que es - integrado en el contexto de la dinámica social en el cual goza de vigencia y sentido. Sin este supuesto no es posible captar con la claridad y coherencia deseables, la situación real; las razones de la necesidad ineludible de corregir y las circunstancias que rodean esta situación, incluyendo la aparentemente inexplicable inoperatividad de nuestras estructuras profesionales. Ahora bien, ello no constituye, en modo alguno, una tarea fácil, pues supone poner de manifiesto el significado operativo de la "realidad como proceson, que en este momento ocupa la atención en los campos más genéricos de la investigación: Biologia, Psicología, Matemática, Fisica, etc. Si a ello añadimos que en este trabajo mi exposición relativa a tal fin no puede rebasar un par de páginas, es evidente la dificultad de este empeño que por otra parte no quiero omitir, en orden a dotar de la máxima coherencia y gene-

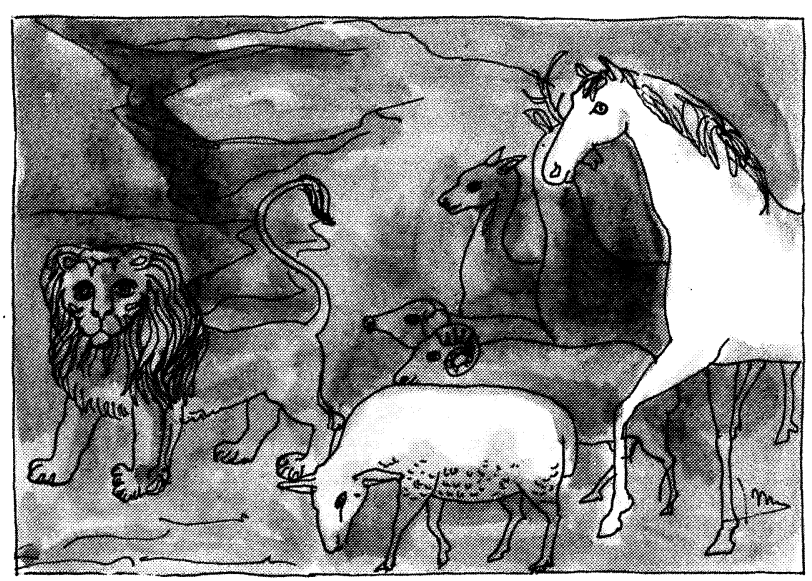

El animal, tanto en su estructura física como en su modo y ámbito de actuación también cumplimenta la definición de sistema. Los ámbitos de actuación del animal y del vegetal constituyen "compartimentos» fijos y cerrados, en el sentido de que a través de su desarrollo en el tiempo no amplian, gradualmente, su entorno operativo, su ámbito de actuación: En el mundo vegetal y animal el acceso a nuevos sentidos de actuación ha exigido la aparición de nuevas especies.

ralidad al planteamiento. A tal fin voy a esforzarme por resumir, en una esquematización máxima y con la más llana y asequible de las terminologías, algunos de los significados más controvertidos y que se vienen considerando más profundos en el campo de la investigación. (Véanse también los textos que complementan las ilustraciones). Si no consigo plenamente este objetivo, ruego al lector tenga en consideración la dificultad del empeño.

\subsection{El proceso de la dinámica social como "sistema" (1)}

Bajo el supuesto de la "realidad como proceso" - cuya determinación, como he dicho, constituye el objetivo de la investigación estratégica más avanzada - (2), la "realidad" tiene consistencia a lo largo de un proceso - histórico- que implica un "sistema" de acción -y pensamiento- corporizado en la actuación de la sociedad, a través de todos y cada uno de los medios e instrumentos de la estructura social: ciencias, órganos sociales y políticos, instituciones, cuerpos de actividades, tecnologias, etc., medios que se caracterizan porque su diversidad de actuación viene informada o imbuida por un sentido unitario de acción. Entiendo que el camino más práctico - 0 acaso el único- para expresar el significado de este supuesto, aplicándolo al tema que nos ocupa, es el de ofrecer una serie de imágenes operativas:

a) Consideremos, en primer lugar, una de las típicas definiciones de "estructura" -que aquí denominaré "sistema»-:

... «es una configuración de la realidad, que forma un todo, de tal forma, que la organización y el trabajo de cada parte están condicionados, a su vez, por el todo, y por eso mismo - las partes - sólo son comprensibles en función del todo»... (Spranger).

b) Comprobemos la definición de "estructura" - "sistema" - en un primer ejemplo auxiliar: Supongamos una máquina de cierta complejidad destinada a la fabricación de cajas de cambios de automóviles e integrada -como es natural- en una gran factoría destinada a la fabricación de un determinado tipo de automóvil.

Es inmediato comprobar que la máquina que consideramos, responde y cumplimenta la definición de Spranger para "sistema". Ahora bien, ¿cómo hemos de interpretar el "todo"? o dicho de otra manera ¿constituye la máquina en sí, un "todo", un sistema? Comprobamos inmediatamente que la máquina, en sí, no constituye un "todo" ya que la máquina sólo "es comprensible" en función de la factoría, puesto que las cajas de cambio adquieren su sentido y razón de ser al integrarse en los automóviles y en particular en el tipo de automóvil que fabrica la factoria. En consecuencia, la máquina constituye un "subsistema" que se hace "consistente" al considerarlo integrado en el sistema, de superior nivel, factoria. (Aquí aparece explicitamente el significado práctico del famoso teorema de Gödel).

(1) Utilizo el término "sistema» preferentemente al de "estructura» porque entiendo que éste implica un significado estático en tanto que el proceso o sistema a que nos referimos es un proceso dinámico, en sí mismo, evolución.

(2) Al final del artículo ofrezco una selección de obras que entiendo muy convenientes para aquel que pretenda familiarizarse con los significados científicos que muy próximamente nos van a ser imprescindibles. 
En resumen, en este ejemplo, la máquinacompleja que estamos considerando constituye, entre otros muchos de la factoría, un subsistema, cuyo sentido de actuación responde al sentido unitario - al cual responden también los restantes subsistemas - de la citada factoría.

c) Consideremos la labor de los técnicos especialistas encargados específicamente de esta máquina compleja: Es evidente que a estos técnicos les es posible, en su trabajo, tratar a la "máquina" como un elemento autónomo y aislado - como un "fin en sí mismo"- en tanto el sentido de actuación de la máquina siga concordando con el de los demás «subsistemas" de la factoria. Ahora bien, si a lo largo de una complejización y perfeccionamiento cada vez mayor, de cada una de las complejas máquinas que constituyen la factoría - en virtud de la gran especialización de cada grupo de técnicos específicamente dedicados a ellas - se fuera perdiendo de vista

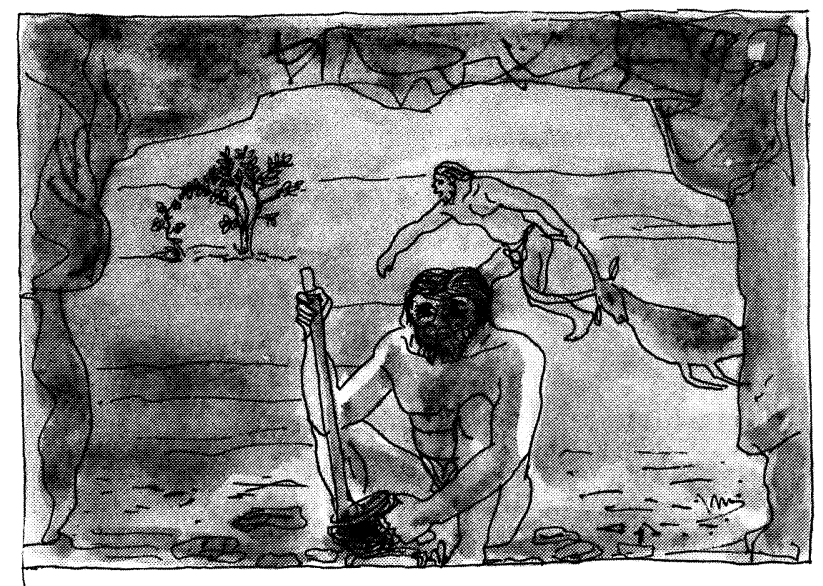

El hombre, como animal que es, cumplimenta la definición de sistema pero de modo peculiar respecto a vegetales y animales: Se realiza en el sistema "sociedad" de tal modo que gradualmente va accediendo a ámbitos de realidad -actuaciónmás amplios en el proceso evolutivo de su realización o desarrollo. El acceso a "nuevos sentidos de actuación" tiene lugar a través de la evolución de su conocimiento - creatividad- es decir, a través de la "ciencia», que dirige el sentido de la acción.

que la razón de ser de cada uno de tales subsistemas, está precisamente en que responden al sentido unitario de la factoria; ocurriria que los especialistas irían convirtiendo las máquinas, de "medios" en "fines", momento en el cual la factoria quedaría desintegrada $e$ inoperante - a pesar de que cada una de las máquinas siguiera funcionando autónomamente con gran eficacia mecánica- puesto que el rendimiento y existencia misma de la factoría implica la exigencia de que las máquinas trabajen, coherentemente. en orden a un objetivo común (Sin "coherencia» no hay "factoria»).

d) Sobre el supuesto anterior, además - puesto que en la práctica se da paralelamente- po- demos considerar otro supuesto: A medida que los especialistas van perfeccionando $y$ complejizando más y más su trabajo y se van acercando al límite cuantitativo de perfección y complejidad que admite ese tipo de máquina o ese tipo de producto, supongamos, que (en razón a los graduales descubrimientos que, precisamente, el desarrollo de la industria va proporcionando) se hace posible concebir y realizar un nuevo tipo de máquina, para fabricar: o un nuevo tipo de caja de cambios, o un automóvil, mucho más eficaz que el anterior y "cualitativamente distinto" del mismo (es decir que no viene concebido y realizado como consecuencia de proseguir el mismo sentido perfeccionando y complejizando). Es evidente que en tal caso, si los técnicos de la factoría en cuestión influidos por la visión parcial que tienen de la factoría (cada grupo dedicado a su máquina específica, a la que considera como autónoma y autosuficiente) son incapaces de plantearse un cambio cualitativo en la actividad, el rendimiento de la factoría se irá gradualmente deteriorando, tanto por la actuación dispersa de cada una de las máquinas, como porque el producto obtenido no responde ya al nivel que exige el momento. La factoria seguiría, en tal caso, trabajando, "fuera de la realidad" correspondiente al nivel del momento, y su deterioro y degradación la llevarian a una rápida ruina (3).

Una vez que hemos considerado esta imagen, basta, simplemente, trasladarnos del sistema -aparentemente mecanicista - "factoria", al sistema orgánico "sociedad", al que he hecho referencia inicialmente. (No debe entenderse aqui que al tratar de la sociedad como "sistema", me refiera al significado rígido y reduccionista de "estructura" o "sistema" más usual, como el propio, por ejemplo, de Levi-Strauss. El significado de "sistema", no reduccionista, que corresponde al hombre realizándose en la sociedad y al que me refiero es el implícitamente desarrollado en la obra de Faustino Cordón "Historia natural de la acción y experiencia" - "La alimentación base de la Biologia evolucionistan. Lamento vivamente la necesidad de limitarme, en esta materia, a la simple operatividad de las imágenes).

Al igual que la "dinámica de actuación» de la factoría se realiza a través de la acción de máquinas diversas, integradas como "subsistemas" en el sentido del conjunto; y al igual que dentro de cada máquina - subsistema- podemos considerar diversos "subsistemas" de orden diverso: elementos complejos de la máquina; piezas complejas de estos elementos; piezas simples dentro de las complejas, etc.; nuestra "dinámica social" se realiza a través de infinidad de "subsistemas" o

(3) Este ejemplo, por otra parte, no es un ejemplo imaginario, sino que expresa el proceso real del acontecer industrial. 
instrumentos de actuación que, a pesar de su variedad y aparente autonomía, han de actuar "coherentemente" (Al igual que hemos comprobado en los medios de la factoría). Bajo tal supuesto, podemos definir la Ciencia como el pensamiento que guia el sentido de la acción. Vivimos un momento -en analogía a lo expuesto para la factoria- de complejización máxima o final de una fase "cualitativa" en el proceso de nuestro "desarrollo»; que exige un "cambio cualitativo", lo cual supone, en el campo de la ciencia, el acceso a un nuevo origen axiomático de las ciencias y en el campo de nuestra vida práctica un "cambio de mentalidad". Ello explica toda la sintomatología actual, en todos los órdenes y el por qué vivimos una época que cada vez más generalizadamente se califica como época de crisis. Es en este contexto, en el que es preciso considerar nuestro "subsistema" Construcción, y es en este contexto en el que se hace patente la exigencia de su genérica corrección, en orden a la cual el especialista que sea incapaz de rebasar cualitativamente su campo de visión no tiene nada que decir hacia el futuro.

2. DESFASE ENTRE EL SENTIDO DE NUESTRA ACTUACION Y LAS EXIGENCIAS DEL NIVEL ACTUAL. PERJUICIOS QUE SE SIGUEN DE ESTE DESFASE: PARA LA SOCIEDAD Y PARA LOS PROFESIONALES

... «A menos que estemos dispuestos a enfrentarnos, individual y colectivamente, con las catastróficas consecuencias universales del fenómeno tecnológico, la discusión de nuestros pequeños problemas domésticos puede resultar intrascendente»...

(Félix Candela.

Ponencia 2. ${ }^{a}$ del XII Congreso UIA)

Ya hemos visto en el apartado anterior cómo, al contemplar la actividad de la Construcción como uno de los medios o "subsistemas" de actuación a través de los cuales se expresa la «dinámica socialn, y diagnosticada la exigencia ineludible de un cambio genérico de sentido en nuestra dinámica social -cambio cualitativo- se diagnostica, consecuentemente, la exigencia de un cambio de sentido cualitativo en la actividad de la Construcción y queda determinada y clarificada la situación en que nos encontramos, y sus circunstancias. En consecuencia, los argumentos que aquí ofrezco desde el ámbito de la Construcción están implícitamente apoyados por argumentos mucho más potentes - porque son mucho más genéricos- que enlazan con las primeras fuentes de investigación.

Ahora bien, a partir de este momento abandono por completo los planteamientos genéricos para entrar en los problemas que, en la práctica, saltan a nuestra vista en el ejercicio cotidiano de nuestra actividad.

\subsection{Desfase entre el tratamiento técnico-legal y la realidad}

Debo hacer referencia a una reducción esquemática de la definición operativa de "creatividad arquitectónican (1) que obtuve -XII Congreso UIA- a través de 136 encuestas correspondientes, prácticamente, a todos los países del mundo:

«El conjunto Proyecto-Realización de obra, consiste en un proceso destinado a la resolución de un problema - programa - de acuerdo con un sentido estratégico -orden de prioridades- de modo que todos los medios de actuación -materiales, elementos, tratamientos y tecnologias - vayan dirigidos precisa y exclusivamente - concepto de economía - a la consecución de aquel sentido estratégicon.

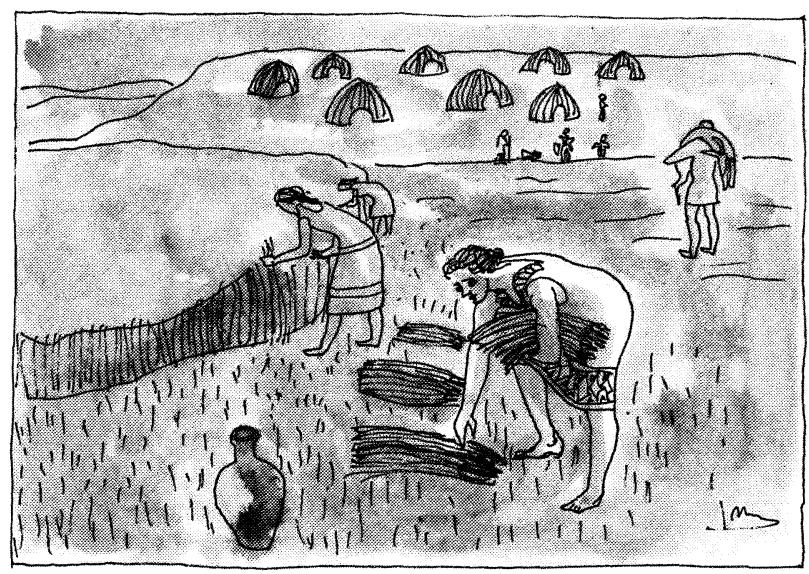

La realización del hombre se da en paraleló con su acceso a niveles cada vez más elevados de conciencia, de modo que el «sistema va evolucionando hacia una complejización de relaciones: la relación entre "parte" y "todo" ha de cumplimentarse, pero en un campo cada vez más y más complejo y rico en relaciones,
en "partes" - "compromiso" entre unidad y diversidad-. En los origenes del en "partes" - "ccompromiso" entre unidad y diversidad-. En los origenes del sobre la "parte". (Estos sistemas son los estudiados por Levi-Strauss).

Entiendo que el lector puede fácilmente comprobar esta definición contrastándola con los supuestos del ejercicio práctico profesional.

Si analizamos el proceso de la obra de construcción tal como la hemos definido, nos encontramos inmediatamente con la alternativa de que ésta puede ser considerada, bien en un campo muy simple, o bien en un campo muy complejo de relaciones. Al cumplimentar o tratar de cumplimentar el objeto del programa, de acuerdo con las prioridades que el caso concreto implique y a partir de los medios - materiales, elementos, tecno-

(1) Genéricamente aplicable a toda obra de construcción. 
logias - ... con que contemos, puede plantearse el problema de modo que el número de variables a utilizar - la "densidad de relaciones" - sea muy limitado; o por el contrario, notablemente elevado: programas muy simples, sin matización apreciable de prioridades y con una gama muy reducida de medios; o bien, programas muy complejos con una gran alternativa de prioridades y con una gama casi indefinida de materiales, elementos y tecnologias ... Pues bien, en esta alternativa de contrastar la muy compleja situación de relaciones actual con la muy simple -0 relativamente muy simple- correspondiente a principios de nuestro siglo -o incluso sólo cincuenta años atrás-es en la alternativa en que nos encontramos, dado que el sentido a través del cual estamos planteando nuestra actuación corresponde al supuesto de un campo simple de relaciones. Nos encontramos, por tanto, en una situación de desfase, cualitativamente hablando, puesto que -como vimos en el apartado anterior - a partir de una determinada "densidad de relaciones", el problema pasa a ser "cualitativamente" distinto (2), por lo que, a fin de

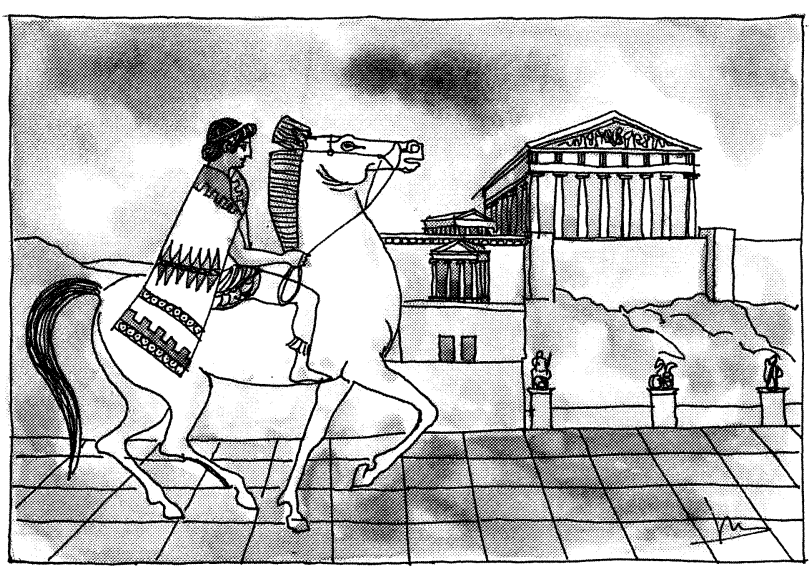

En el proceso de realizacion del hombre, la concurdancia de sentido de la "parte» con el todo supone la "comunicación" y la amplitud del campo de relaciones supone la «información». (De aqui la correspondencia, hasta ahora no explicada, entre «información» y "entropía»). Ahora bien, la complejización de relaciones en la evolución del sistema no se da a través de un "sólo impulso". sino a través de sucesivos y profundos "saltos» cualitativos. Así: el hombre paleolitico, el hombre sedentario, la ciudad estado...
(2) Este supuesto ya fue señalado por Félix Candela en su Ponencia "Influencia de la Tecnoiogía en la Creatividad Arquitectónica» del XII Congreso UIA, si bien no aportó otras indicaciones hacia el camino de su diagnóstico y corrección:... «En la urgente búsqueda y hallazgo provisional de soluciones a problemas sociales inaplazables, la tecnología pone a su servicio un conjunto de técnicas especializadas que desarrollan a sú servicio un conjunto de técnicas especializadas que desarrollan mismo tiempo, organismos capaces de manipularlos con destreza y eficacia. Pero la introducción y uso de estos mecanismos originan... una serie de cambios fundamentales en los problemas que trataban de resolver. Sus efectos secundarios alteran $y$, en cierto modo, destruyen la sociedad cuyo funcionamiento se intentaba regular, transformándola en otra cuyos inusitos pros inusitados problemas requieren la aplicación de una nueva tecnología. Se origina asi un círculo vicioso del que no parece fácil escapar»... Hemos visto que este "círculo vicioso", al menos en cuanto a la determinación de su significado y clarificación, se rebasa a la luz de la urealidad como proceson: Se trata del proceso de complejización de relaciones que va dándose en sucesivas fases a través de correcciones cualitativas de sentido. cuentas, nos encontramos tratando de acometer y resolver determinados problemas a través de unos medios dirigidos en el sentido correspondiente a la resolución de problemas distintos.

\subsection{Perjuicios que se siguen, para la sociedad, como consecuencia de este desfase.}

El perjuicio - genéricamente hablando- que este estado de cosas supone para la sociedad salta a la vista con sólo considerar que la Construcción constituye uno de los medios o "subsistemas", fundamentales a través de los cuales se corporiza la estructura de la sociedad; por lo cual, no es necesario encarecer su incidencia social y económica.

Por otra parte este supuesto es verificable de inmediato, pues basta considerar y analizar el fenómeno que denominamos uinflación" para diagnosticar, con toda facilidad y certidumbre, que uno de los factores con mayor incidencia en tal fenómeno, viene constituido, precisamente, por el desfase que se da en la actividad de la Construcción (3).

Como es bien sabido el fenómeno «inflación" al que generalmente se asigna significado -exclusivamente- económico, no ha podido ser definido por los economistas, coherentemente, en el contexto de las leyes hasta ahora consideradas vigentes; y la aparición, en estos últimos tiempos, de una inflación generalizada y admitida como irreversible, no es consecuente con tales leyes. En contraste, el significado de "inflación» queda perfectamente determinado y clarificado a la luz de la "realidad como proceso", que hemos tratado esquemáticamente en el apartado 1; y por otra parte este significado es tan evidente que, tal como a continuación comprobaremos, con sólo exponerlo, se excluye toda posibilidad de combatirlo:

En un proceso en evolución, en el que gradualmente van surgiendo nuevos problemas que acometer y resolver, el sentido de los medios de actuación para acometerlos ha de estar en concordancia con el sentido de los problemas a resolver; es decir, ha de evolucionar en concordancia con la evolución de los problemas.

Bajo tal supuesto, se dará un gran rendimiento en los resultados; dicho de otro modo: se dará un buen rendimiento "económico" en el desarrollo de una actividad cuando los medios estén en concordancia entre si y adecuados a los fines (4). Por el

(3) No quiero decir que se dé una relación "causal»; es decir, que el desfase que nos ocupa sea, de por sí, el causante de la inflación. E "desfase» es una de las consecuencias de la situación genérica de desequilibrio; si bien para promover la corrección del desequilibrio uno de los aspectos más importantes a corregir es el relativo al desfase en el ámbito de la Construcción.

(4) Compruébese que este supuesto constituye, precisamente, la definición operativa de "economía». En rigor la única definición de economía -al menos que yo conozca - coincide, precisamente, con la definición de «realidad» como proceso y ello es sumamente significativo en el contexto de los campos más genéricos de investigación. 
contrario, cuando los diversos medios de actuación no van dirigidos en un sentido unitario y (o) el sentido de tales medios no está en concordancia con la problemática a resolver, no puede darse, en modo alguno - ello es evidente- un satisfactorio rendimiento en la actuación, dando lugar al fenómeno que venimos denominando "inflación" (5). Los ejemplos son inmediatos: el hombre se realiza a lo largo de un proceso en evolución; en su edad, por ejemplo de cinco años, a su problemática - «sentido de la realidad»- ha de enfrentarse con unos medios - de captación, relación comunicación, nutrición, etc. - concordantes con tal problemática, que son los correspondientes a aquella edad; pero ese mismo niño cuando alcanza la edad de treinta años, a la cual corresponde una problemática distinta, habrá de contar con unos medios cuyo sentido tiene, necesariamente, que ser distinto del anterior y concordante con las exigencias del nuevo nivel. $Y$ aún cabe un ejemplo más directo y sencillo: Si yo salgo un día al campo, dispuesto a cazar, habré de proveerme de una escopeta; pero si al día siguiente he de

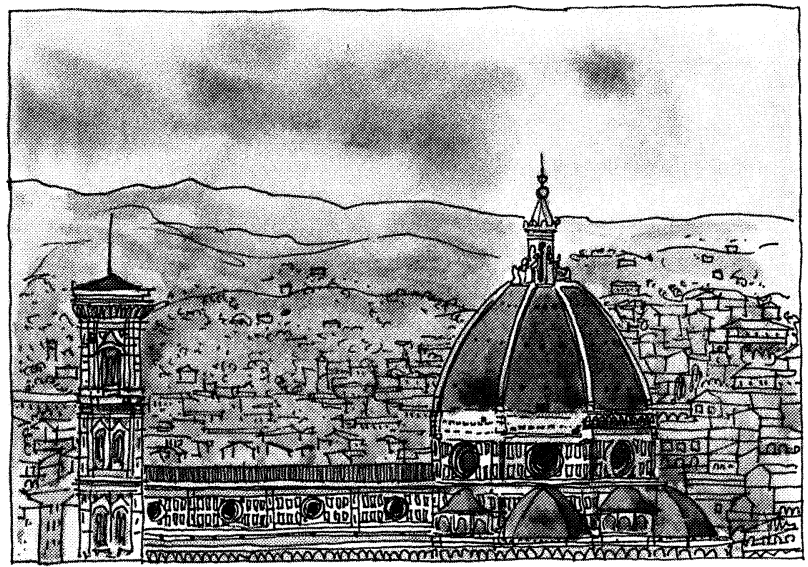

Toda realización del hombre - producto de su creatividad - : teoria cientifica, ins trumento, objeto, obra de arte, máquina, artefacto, etc., cumplimenta la definición de sistema, como puede comprobarse de modo inmediato. Si nos referimo a los campos del urbanismo, arquitectura y construcción, podriamos seguir, perfectamente, el proceso de complejización o densificación de relaciones - creatividad - que se da en los tres aspectos a lo largo de la historia. Así, conocemos - por Vasari- cómo la construcción de la cúpula de Brunelleschi exigió un cambio sobre el sentido de actuación anterior.

cambiar - por las circunstancias que fueren- el ejercicio de la caza por el de la pesca, me veré absolutamente obligado a sustituir la escopeta - instrumento que carecería ya de sentido- por una caña de pescar; ya que en caso contrario es seguro que obtendré un rendimiento muy bajo en la nueva actividad.

Salta, pues, a la vista el error de los economistas convencionales que asignan a la "Inflación" una naturaleza "dineraría" o al menos "específicamente

(5) Este significado es homólogo al de «entropia» en el campo de la Fisica. Se define la "entropia», como la medida que cuantifica la energía de un sistema que no es susceptible de ser transformada en "trabajo». - Siendo así que el significado de "trabajo» en la Física es homólogo a nuestro significado de usentido»-. económica»: la secuela "económica", o falta de rendimiento, tiene lugar como consecuencia de que se trata de acometer y resolver problemas nuevos -implicados en el nivel de evolución a que accedemos - sin adecuar los medios al sentido que tales problemas exigen.

Supone pues la inflación, una persistencia del sentido anterior -inoperante hacia el futuro- que va gradualmente convirtiendo los medios en fines a través de la burocratización de la estructura y como consecuencia de la incapacidad de ésta para corregir cualitativamente el sentido de su actuación.

Bajo esta luz, queda perfectamente clarificada esta situación que venimos constatando de que nuestras estructuras, en general - políticas económicas, profesionales, institucionales, etc. - cada vez se vengan revelando más inoperantes, pasivas, y desconectadas de los verdaderos problemas que nos acucian: esta situación, por otra parte, se irá agudizando; ya que a medida que nuestras estructuras se burocratizan -al afirmarse más y más en el sentido antiguo, convertidos los medios en $\mathrm{fi}$ nes- van incorporando las mentalidades menos creativas y más burocráticas aumentando así en incapacidad para resolver los problemas.

\subsection{Perjuicios que se siguen, para los técnicos, como consecuencia de este desfase}

Anteriormente, al referirme a los perjuicios que se siguen para la sociedad me he limitado a englobarlos genéricamente en el significado de "inflación" - que se viene calificando como el "mayor obstáculo al desarrollon - pero ahora, al tratar de los perjuicios que se siguen para los técnicos, entraré en la enumeración de algunos de los aspectos más acuciantes y significativos, si bien bajo un esquematismo máximo, dada la amplitud potencial de la materia. Naturalmente al especificar estos perjuicios estaré indirectamente especificando perjuicios que se siguen también para la sociedad, puesto que ambas calificaciones no son sino expresiones de un mismo problema contempladas desde distintos puntos de vista (6).

En la época de principios de siglo, e incluso hasta hace unos cuarenta o cincuenta años, la Construcción respondia a un proceso muy simple:

a) Las realizaciones de obra se basaban en la utilización de una serie de materiales muy convencionales - ladrillo, piedra y más tarde acero y hormigón - cuyas variantes de tratamiento, normalmente in situ, daban lugar a los elementos y soluciones.

(6) Insisto en que las consideraciones que hago provienen del estudio y análisis del proceso y problemática de la Edificación en nuestro pais aun cuando en grandes líneas son aplicables a la Construcción en genera $y$ al ámbito geográfico del mundo que denominamos «occidental». 
b) No se daba alta diversidad ni complejidad de programas, de instalaciones ni de sistemas constructivos y no existía, prácticamente, industria complementaria, ni tecnologías complejas relacionadas directamente con la Construcción.

En consecuencia, el Proyectista y Director de obra dominaba el proceso en su conjunto y en su detaIle, proceso consistente en manejar los materiales y métodos convencionales - cuya funcionalidad y prioridades eran, por así decirlo, de «dominio públicon - para obtener, a partir de su realización in situ, soluciones correctas.

En función de estos supuestos tomaron cuerpo y vigencia legal los instrumentos correspondientes a la actividad con que actuamos:

- Funciones y atribuciones del Proyectista y Director de obra así como de los técnicos implicados directamente (que en el caso de la Edificación lo era el Aparejador; en tanto que el resto de los técnicos no tiene cabida legal en la actividad) y papel del Constructor, del cual no se exige cualificación titulada.

- Estructuración y contenido del Proyecto: Memoria, Presupuesto y Pliego de Condiciones en su naturaleza actual.

- Relaciones entre las actividades de la Construcción y la industria relativa o complementaria a la misma - sean consideradas por determinación explícita, o por omisión-.

Tales instrumentos legales son los que siguen vigentes en la actualidad, a pesar de que, como hemos dicho, la naturaleza práctica de la actividad ha cambiado cualitativamente, como consecuencia de la complejización del proceso de relaciones:

a) La mayor parte de las realizaciones de obra vienen ya -0 deberian venir - suministradas por la Industria (Todas las posibilidades de incremento y desarrollo de la actividad están supeditadas a que tal condición se vaya acentuando).

b) Se da un alto grado de diversidad y complejidad de programas, de instalaciones y de sistemas constructivos, con tendencia continua a ampliarse.

c) Se da la exigencia, gradualmente en aumento, de la participación de técnicos en especialidades diversas, si bien el sentido de estas especialidades ha de estar siempre dirigido en un sentido unitario, de acuerdo con el objetivo y prioridades a que debe responder el planteamiento de la obra.
- En resumen, se da la exigencia de un sentido unitario de actuación compatible con una alta diversidad y complejidad de medios y tecnologías, supuesto que se encuentra en contradicción con el tratamiento técnico-legal vigente.

Las tentativas que puedan haberse realizado, si puede hablarse en rigor de tales tentativas (7), para corregir este estado de cosas, no han incidido para nada en la corrección del desfase genérico de la situación; y en este momento se da un estado de total incomunicación -es decir, falta de sentido, de coherencia- en el contexto del proceso de la Construcción con la consiguiente secuela de perjuicios para cuantos factores intervienen en la misma, algunos de los cuales señalo esquemáticamente a continuación:

\subsubsection{Funciones y responsabilidades de los técnicos}

Las atribuciones de los técnicos, así como su calificación específica, deben ser consecuencia de las funciones que exija la naturaleza de la activi-

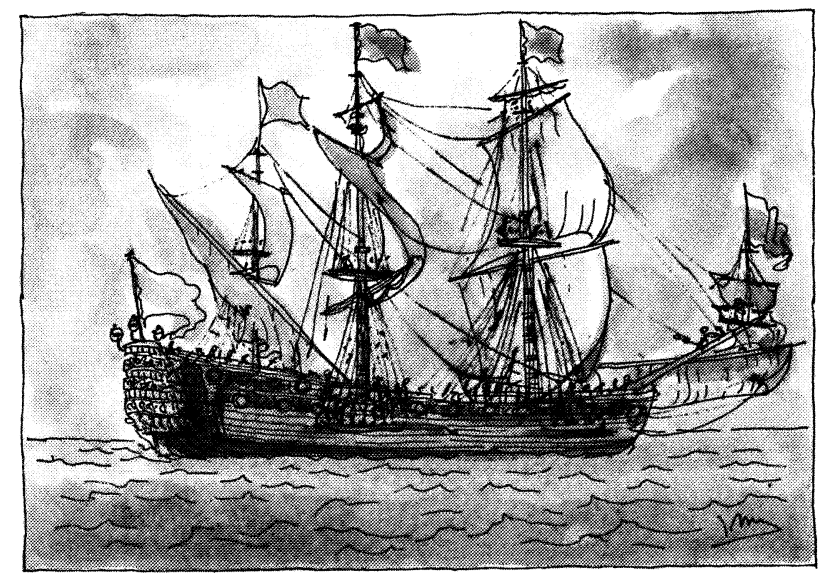

Si consideramos una máquina, a primera vista, parece constituir un «mecanismo o sistema sin capacidad de evolución. Ello se debe a un planteamiento inconsecuente; considerada la máquina en el contexto del proceso de creatividad del hombre - como corresponde - está expresando un estadio concreto y particular del proceso evolutivo. Ahora bien, no es válido - como hace la Prospectiva extrapolar hacia el futuro a partir de un sistema «mecanismo».

dad correspondiente. Al haberse modificado, de hecho, la naturaleza de la actividad, sin haber corregido paralelamente las atribuciones en correspondencia con ésta, se da una situación de confusionismo altamente negativo para el profesional, ya que:

- Impide o desvirtúa su actuación creativa, imposibilitándole prácticamente la identificación entusiasta con su labor.

- Sitúa al técnico en una posición inestable, en la que las funciones y responsabilidades que-

(7) Que de ser consideradas como tales, no to han sido, desde luego, como operaciones conscientes tendentes a corregir una situación en crisis. 
dan difuminadas; y frecuentemente, carga sobre sus espaldas responsabilidades que por naturaleza no deberian corresponderle (8).

- La falta de un "seguro obligatorio" de responsabilidades -exigida por la propia naturaleza de la actividad actual - asignado a la actividad misma y no a la persona del técnico, convierte el ejercicio profesional en una aventura ciertamente peligrosa, que atrae frecuentemente las actuaciones al campo penal, en la natural búsqueda por parte del juez de una compensación rápida a los perjudicados (Se viene diciendo que la legislación carga exclusiva e indiscriminadamente toda responsabilidad sobre el Arquitecto, pero tal afirmación no es, en modo alguno, exacta. Las especificaciones legales son genéricas - lo cual es un acierto-; lo que falta es una adecuación de lo genérico a las circunstancias reales, gestión ésta que, naturalmente, debiera haber sido promovida por los propios técnicos) (8).

Todas las tentativas que se han venido realizando desde el ámbito de la Administración para reajustar y poner al día las atribuciones de los técnicos, han fracasado, convertidas en meras tentativas de mantener parcelas de atribuciones anejas a la titulación, sin profundizar en modo alguno en la materia y sin tener en cuenta que la mejor fórmula para el mejor encaje -y por tanto beneficio- de todos y cada uno de los diversos técnicos es precisamente la creación de "comunicación", de coherencia, en el contexto de la actividad (Al igual que la máxima vigencia de todas y cada una de las piezas de un "rompecabezas" se logra cuando en el rompecabezas se pone de manifiesto la vigencia de un sentido unitario de conjunto) (8).

\subsubsection{La Construcción y la Industria}

Uno de los sectores más perjudicados por el estado de "incomunicación" que afecta al proceso de la Construcción en su contexto, es el sector de la Industria; y ello resulta tanto más grave en cuanto que las expectativas de incremento $-y$ desarrollo mismo- de la actividad, están, necesariamente, supeditadas a un correcto encaje industrial en el proceso de la actividad. La "incomunicación", consecuencia del desfase, afecta bajo muy diversos aspectos al correcto encaje de la Industria:

a) El Proyectista, hoy, para proyectar con rigor, eficacia y conocimiento de causa, necesita conocer la adecuación, sentido y alcance de los diversos elementos, sistemas y tecnologías

(8) Esta problemática está tratada con cierta amplitud y más o menos directamente o indirectamente en la obra "Proyecto, Realización y Con-
servación de la Estructura». J. Martínez Calzón y J. Martitegui. Tomo 2 de "Cuadernos de Planeamiento". que la Industria proporciona; así como la gran variedad de matizaciones - prioridades - que ofrece hoy la técnica especializada.

Solamente en estas condiciones el Proyectista puede aprovechar la eficacia y matización que las tecnologías le ofrecen, y cumplir, al máximo, su función de elegir, coordinando, para obtener la óptima resolución.

(En último término, la redacción de un Proyecto consiste en resolver la serie de problemas parciales que constituyen el proceso, eligiendo aquellas soluciones - soluciones técnicas, materiales, sistemas o tecnologíasmás adecuadas al sentido integral del Proyecto, fijado por el conjunto: programa-terrenoentorno-circunstancias específicas. Un Proyecto estará tanto mejor logrado, cuanto mayor sea el número de resoluciones parciales justificadas, lo cual exige una labor eminentemente de elección y supone una perfecta y exhaustiva información tecnológica).

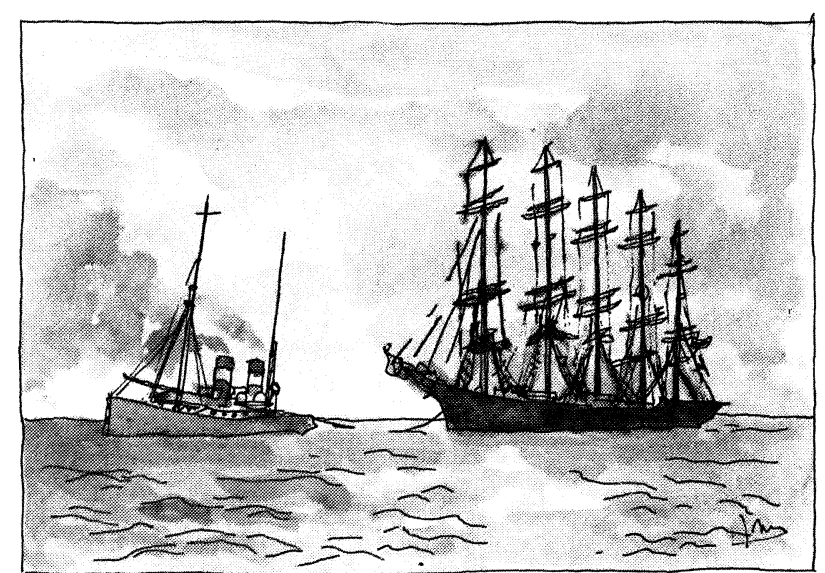

Hemos visto que la evolución del sistema - complejización de relaciones - tien lugar, en su contexto, a través de profundos saltos cualitativos de sentido. En estos grandes ciclos, la evolución de los subsistemas se da, a su vez, a través de cambios cuantitativos - dentro del mismo sentido - $y$ cualitativos compatible con el "sentido estratégico" que caracteriza a la fase vigente. Por ejemplo, la navegación a vela admitió perfeccionamiento hasta un límite. (En la ilustración,

b) La "comunicación» entre la Industria y el Proyectista constituye también un supuesto imprescindible, si tenemos en cuenta la relación "medios", "prioridades", es decir si tenemos en cuenta que son las "adecuaciones funcionales" de los materiales, elementos y tecnologias, las que se traducen en posibles matizaciones o prioridades del programa; de modo que una correcta comunicación Proyectista-Industria, no sólo facilitaria el intercambio de sus respectivos requerimientos -Proyectista- y posibilidades - Industria - sino que permitiria a la Industria "estar al dia" sobre las exigencias funcionales de los programas y sus circunstancias, facilitándole dirigir sus in- 
vestigaciones hacia los objetivos más estratégicos y rentables.

c) Al margen de estas exigencias de "comunicación", para lograr un buen encaje de la Industria en el proceso, la "industrialización» propiamente dicha (9) requiere en todo caso un cambio en el sentido de la actividad de la Construcción -cambio cualitativo-.

Quiero hacer notar la concordancia global de este supuesto, que viene deducido de la coherencia de un planteamiento integral, con las conclusiones de Julián Salas en su obra, recientemente editada por el Instituto Eduardo Torroja, "Alojamiento y Tecnología: ¿Industrialización abierta?", conclusiones éstas que vienen fundamentadas en el estudio y experiencia sistemáticos y documentados del hecho práctico de la industrialización. tos diversos de la actividad; pero por su importancia no puedo dejar de hacer una referencia a los siguientes:

- La Metodología, en general, se encuentra absolutamente desfasada: el sentido de la bibliografía hace a ésta prácticamente inoperante; el sentido de la documentación del Proyecto es el correspondiente a cincuenta años atrás; y no se cuenta - ni al parecer se busca- con instrumentos informativos $y$ operativos que permitan plantear la documentación a la altura de las circunstancias.

- La Enseñanza merecería un tratamiento aparte, ya que si fuera posible, dentro del confusionismo total, señalar lo que ha alcanzado mayor deterioro y desviación, el mérito le corresponderia al capitulo de la Enseñanza

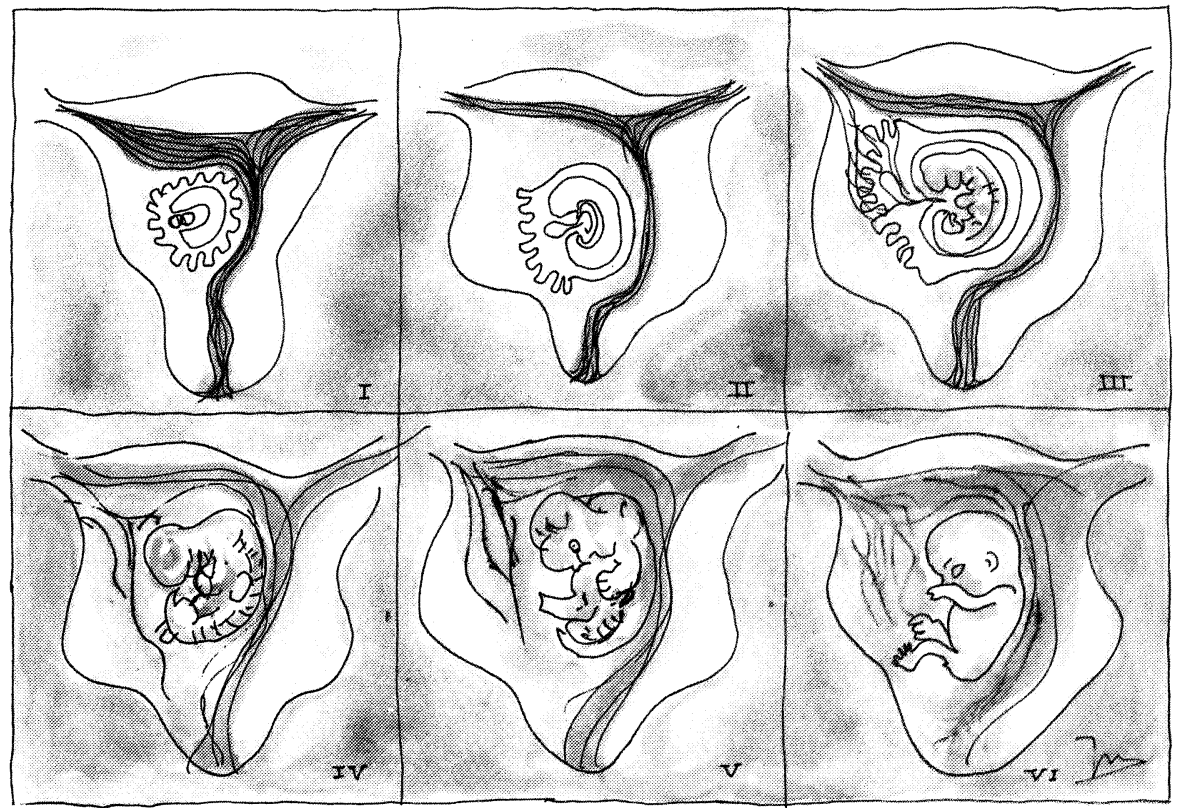

Se puede determinar el diagnóstico de nuestra situación actual - exigencia de un profundo cambio cualitativo - considerando en el proceso de realización del hombre, su etapa o fase «prenatal», que comprende desde la concepción hasta el nacimiento. De acuerdo con la definición de sistema, durante tal etapa el sentido del organismo en realización ha de ser concordante con el sentido de actuación de su entorno. Si analizamos en qué consiste, en esta fase "pre-natal", la realización del organismo, que evoluciona desde la simplicidad de relaciones del embrión hasta la complejidad de relaciones del organismo apto para el nacimiento, comprobaremos que consiste en irse dotando de los medios adecuados al sentido de actuación que corresponderá al nivel o estadio siguiente del proceso de su desarrollo. Ahora bien, la utilización de tales medios formados a lo largo de esta ase prenatal, exige un drástico cambio cualitativo de sentido: el nacimiento a un nuevo sentido de la realidad, ya que organismo si persistiera en el anterior

\subsubsection{Otros perjuicios como consecuencia del desfase, en los campos de la Metodologia, Enseñanza y aplicación de funciones profesionales}

La limitación que impone la amplitud de un artículo me impide seguir exponiendo, aun con este esquematismo, una enumeración exhaustiva de los graves desajustes y perjuicios en campos o aspec-

(9) Ya he señalado anteriormente que la «industrialización» constituye un supuesto imprescindible para el ulterior desarrollo de la actividad. Es a través de la uindustrialización" como se accede - ver apartado 1en el contexto del proceso de nuestra dinámica social, a la fase consecutiva de desarrollo.
- También se debe poner de manifiesto que este estado de cosas es el principal causante de la imposibilidad de encaje de millares de técnicos en sus funciones - es decir, de su condena al "paro"- ya que vivimos la aparente paradoja de que, aún cuando, en la práctica, se da un vacio en campos potenciales amplisimos del proceso técnico - que bajo el supuesto de un buen servicio a la sociedad deberian estar cubiertos- al mismo tiempo, al no venir corrigiendo el sentido de acuerdo con las exigencias reales; ni venir formando los técnicos adecuadamente; ni venir determinando las funciones de acuerdo con los requerimientos: nos encontramos con que ni la sociedad está servida ni los técnicos tienen posibilidad de servirla. 
3. RESPONSABILIDAD DE LOS TECNICOS ANTE LA SITUACION ACTUAL $Y$ EXPECTATIVAS EN CUANTO A LAS POSIBILIDADES DE CORRECCION

\author{
... «Dejad que los muertos entierren a sus \\ muertos»...
}

\section{(Lucas. Nuevo Testamento)}

Una vez que ha sido puesta de manifiesto la situación y su incidencia negativa en los campos social y profesional; y al mismo tiempo, puesto de relieve que todo esfuerzo o tentativa de mejoras parciales, en uno u otro sentido, carecen de verdadera operatividad en tanto no se promueva la corrección genérica pertinente; procede considerar quienes son, o deberian ser, los llamados a promover la corrección, cómo y a través de qué agen-
Ahora bien, podria objetarse que una situación genérica de desfase que implica un cambio cualitativo de naturaleza, rebasa, en cierto modo, el ámbito propiamente dicho de la Construcción y que sólo es diagnosticable $-y$ consecuentemente, corregible- desde un nivel más genérico, correspondiendo, por tanto a tal nivel la responsabilidad del diagnóstico y la corrección. Pero a esta objeción puede y debe responderse que los técnicos superiores pertenecientes al ámbito de la Construcción venimos proclamando $-y$ actuando profesionalmente en consecuencia- que nuestra formación, capacidad y atribuciones son las más idóneas -o de las más idóneas-, para el ejercicio de la planificación urbanística; es decir que somos urbanistas, o si se prefiere planificadores. Por tanto, si desde nuestra condición de "constructores" podríamos estar exentos de responsabilidad y competencia, no lo estariamos, desde
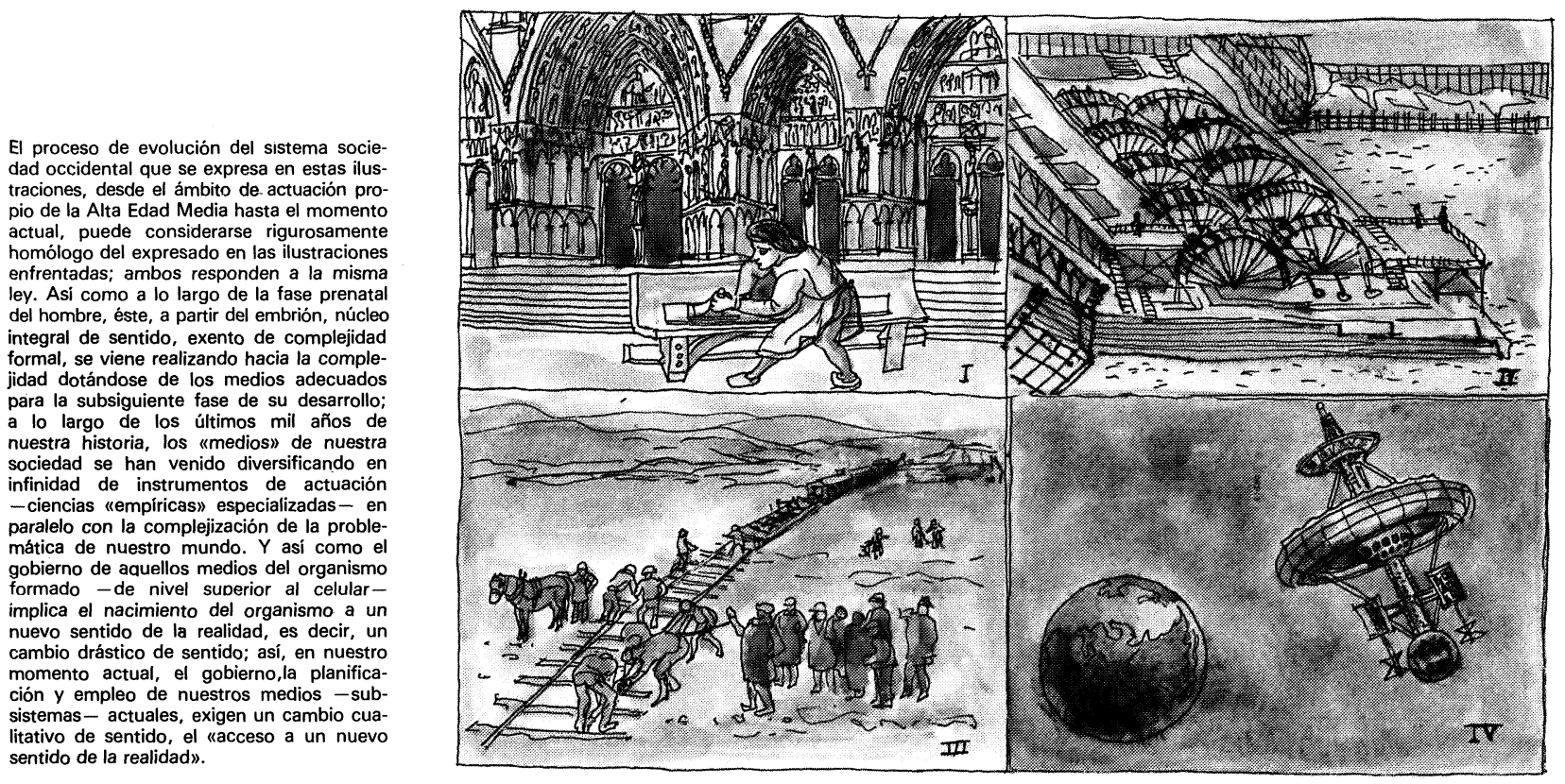

tes podria acometerse, y cuáles pueden ser las esperanzas de que tal actuación se lleve a cabo (Sin esta segunda parte, la primera quedaría limitada a una simple elucubración filosófica, o a lo más, de "técnica aséptica" y yo anteriormente he señalado que al tratamiento de este tema le corresponde una "técnica comprometida" o si se prefiere "operativa", o al menos dirigida hacia la operatividad).

\subsection{A quién corresponde, por naturaleza, acome- ter la resolución de este problema}

Es evidente que, tratar, diagnosticar y resolver, en materias relativas a la tecnologia de la Construcción, es misión de los técnicos y profesionales pertenecientes a este campo específico. No creo que aqui sean precisos otros argumentos. nuestra condición de "planificadores", a no ser que limitásemos nuestra capacidad planificadora al campo rutinario de la matización cuantitativa, reconociéndonos impotentes para un «urbanismo creador".

En resumen, por naturaleza, corresponde a los técnicos y profesionales de la Construcción la responsabilidad de promover las correcciones pertinentes dirigidas a adecuar el sentido de nuestra actuación a las exigencias del nivel actual.

\subsection{A quién corresponde, según normativa legal, acometer la resolución de este problema}

La razón de ser de los Colegios de Arquitectos está expresada en sus Estatutos - aprobados por Decreto 13-VI-31 y confirmados por Leyde4-XI-31- 
así: (1) "ARTICULO TERCERO. El objeto fundamental de los Colegios será procurar que se cumplan en todos los casos los fines que corresponden a la Arquitectura considerada como una función social» (2). "Sin perjuicio de la generalidad de este objeto, les corresponde especialmente»:

$$
\text { * * * }
$$

b) "Intervenir en la redacción y modificación de la legislación vigente en lo que se relaciona con la profesión de la Arquitectura en general. Para el cumplimiento de este fin... podrá el Colegio dirigirse en todo momento a las Corporaciones Oficiales proponiendo aquellas reformas o nuevas orientaciones que tiendan a mejorar la Construcción en sus diversos aspectos sociales»..

$$
* * *
$$

i) "Realizar los fines de carácter científico y cultural que estimen convenientes».

k) "Formar los Reglamentos que fijen las normas técnicas de los diferentes sistemas de construcción $e$ instalaciones y determinar las condiciones que deben reunir los diversos materiales y los medios auxiliares de la construcción»...

Aquí no considero necesario apoyar el contenido de estos textos con otros argumentos, por lo cual, agrupando y resumiendo, podemos afirmar:

Por naturaleza, corresponde la responsabilidad de acometer esta corrección a los técnicos; pero dado que por normativa se asigna, corporativamente tal función a los organismos profesionales, se sigue, de todo ello, que la responsabilidad les compete, en primer término a los organismos y en caso de que éstos demostrasen una notoria inoperatividad -o ineptitud- a los técnicos, en su condición de tales.

\subsection{Expectativas en cuanto a los agentes y a las posibilidades de corrección}

Lo primero que debemos poner de manifiesto, una vez que hemos accedido al contenido de los apartados 3.1 y 3.2 , es que no cabe achacar a la Administración, ni la responsabilidad principal del estado de cosas relativo a nuestro campo especifi$\mathrm{co}$, ni la responsabilidad de no acometer la corrección correspondiente. (Dado el silencio en que hemos venido permaneciendo).

También es preciso reconocer la situación general de degradación de las estructuras que se capta en todas partes y en todos los niveles (3), por lo que los juicios negativos que voy a expresar, con respecto a la actuación anterior y a la capacidad fu-

(1) Supongo que a través de terminología análoga estará expresada la razón de ser de los Colegios de Ingenieros en sus respectivos Estatutos.

(2) Durante la época franquista utilizaba yo continuamente este argumento respecto a la acción de nuestras estructuras profesionales; pero hoy la operatividad real de estas estructuras es inferior, aún, a la de entonces y hoy la utilización de este artículo carece de "agresividad». tura de nuestra estructura profesional (4), son juicios que no entrañan una intención peyorativa - "mirar atrás con ira"-. Se trata simplemente de una constatación práctica, en orden a un fin constructivo: procurar promover, por todos los medios que aparezcan viables, una labor de corrección que es urgentísima y capital, tanto para la sociedad, como para los profesionales. Se trata, por decirlo simbólicamente, de no asistir pasivamente a nuestro propio suicidio sin mover un dedo por evitarlo (Cuento, en referencia a mis relaciones con la estructura profesional, con el bagaje documental suficiente para evitar que en ningún caso mi actuación pueda aparecer como contraria a los Colegios).

Una vez hechas estas observaciones debemos pasar a considerar las esperanzas que podemos poner en nuestros organismos profesionales.

\subsection{Posibilidades y capacidad de los organismos profesionales de los Arquitectos. La actua- ción directa de los técnicos}

Tengo el conocimiento, información y experiencia - datos objetivos y contrastables - suficientes para estar absolutamente persuadido de que a menos que se diera un cambio total en la situación y circunstancias de nuestras estructuras profesionales - lo cual en la práctica, a corto o medio plazo es imposible- las estructuras profesionales de los Arquitectos son incapaces de promover la corrección que nuestra situación exige. Estas estructuras se corporizan concretamente en el Consejo Superior de Colegios -organismo coordinador y representante de los Colegios- en el ámbito nacional; y la Unión Internacional de Arquitectos en el ámbito internacional (5) y están aquejadas de burocratización, y de la inercia correspondiente al sentido antiguo.

En consecuencia, a mi parecer, solamente queda un camino: la acción directa de los técnicos, como tales, que estén persuadidos de la exigencia y urgencia de actuar. Esta actuación, que naturalmente habrá de iniciarse aisladamente, se podrá ir potenciando y sistematizando alrededor de grupos y (o) de publicaciones; y a medida que la situación vaya haciéndose más crítica podrá ir gradualmente presionando, bien en el nivel de las organizaciones profesionales, bien en el nivel de la Administración.

(3) Cuya razón de ser y circunstancias queda coherentemente clarificada a la luz de la "realidad como proceso», tal como esquemáticamente se expresa en el apart. 1 .

(4) Naturalmente me refiero a los Colegios de Arquitectos.

(5) Recientemente ha sido nombrado Presidente de la UIA Rafael de la Hoz. Yo tengo un alto concepto sobre el sentido de responsabilidad y de preocupación de Rafael de la Hoz por estos temas, pero considero imposible que pueda mover hacia la operatividad a un organismo que está convertido en pura burocracia. 
Aun cuando ello parezca una paradoja, nuestra esperanza está en la gravedad de la situación y en la imposibilidad de resolverla a través de las actuaciones rutinarias.

\section{MODO DE PLANTEAR LA CORRECCION}

... «Separa la tierra del fuego, y lo fino de lo grueso, suavemente y con todo cuidado. Sube de la Tierra al Cielo y de allí vuelve a la Tierra, para recibir la fuerza de lo de arriba y de lo de abajo... por ello y de este modo, se obrarán aplicaciones prodigiosas»...

\section{(De la «Tabla Esmeraldina»)}

Para promover y plantear la corrección del sentido de nuestra actividad, en orden a orientarse en concordancia con las exigencias del presente y sobre todo del futuro, habría que considerar muy diversos aspectos que están implicados, más o menos directamente, en el problema y que según sean correcta o incorrectamente tratados incidirán notablemente en la eficacia y nivel de los resultados. Vamos a enumerar algunos de estos factores o aspectos, teniendo en cuenta que la Construcción constituye un "subsistema" dentro del sistema de nuestra dinámica social.

\subsection{Lo que supone corregir un "subsistema"}

Si se pretende operatividad y eficacia real en una actuación (1), la primera condición que hay que cumplir es la de ser "realista" y no pretender de la actuación más de lo que ésta pueda proporcionar, ni perder el tiempo en esfuerzos inútiles; lo primero que procede, pues, es determinar el techo máximo o alcance de una posible corrección, teniendo en cuenta que se trata de corregir un "subsistema" es decir, un instrumento que en su sentido general viene condicionado por estructuras más genéricas cuya posibilidad de corrección no está en nuestras manos.

La actividad de la Construcción como instrumento inserto en nuestra "dinámica social» está relacionada, con respecto a ésta, al igual que un elemento complejo de una máquina está relacionado con la máquina como totalidad; y asi como las modificaciones que pudieran realizarse en el elemento aislado de la máquina serian limitadas, lo mismo ocurre con las posibilidades de corregir nuestro "subsistema".

Un sistema no puede modificarse, sino muy limitadamente, actuando sobre elementos aislados, porque hemos visto en el apartado 1 que "la parte

(1) Este no es el caso de los "Congresos» típicos que normalmente se celebran, y que cuando tratan de temas genéricos son, "por definición» inoperantes. Un Congreso "constituye un éxito" con la simple condición de lograr una buena organización mecánica, social y turística. está condicionada por el todo y sólo es comprensible en función del todon.

Por otra parte debemos considerar, que además de "constructores" somos "planificadores" y que en tal nivel no puede separarse drásticamente lo que sea "construcción" de lo que sea "planificación".

Una vez hechas estas puntualizaciones, los resultados prácticos y realistas que se obtienen, tras el estudio del tema (2), son los siguientes:

- Casi todas las correcciones - por no decir todas- que serían precisas en el tratamiento del Urbanismo para orientarlo en concordancia con las exigencias del presente y del futuro, están fuera de nuestro alcance como profesionales, es decir, están condicionadas a las estructuras más genéricas sociales y políticas; por lo que, para corregir aquéllas, sería preciso, previamente acometer la corrección de éstas (3).

- En contraste, gran parte de las correcciones que son precisas en el tratamiento de la Construcción están a nuestro alcance y se traducirían - unas más y otras menos - rápidamente en notable beneficio para todos los elementos que intervienen en la actividad; en tanto que otra gran parte de las correcciones también están condicionadas a otras estructuras más genéricas.

- En consecuencia los resultados de las Conclusiones habrán de diferenciarse en tres cuerpos:

a) Líneas generales de corrección que serian precisas en la dinámica socio-política, para que puedan promoverse las correcciones necesarias en el campo de la Planificación o Urbanistica.

Esta parte del trabajo constituiria una especie de "Libro Blanco" dirigido a la Administración -y a parlamentarios, senadores, organismos económicos, asociaciones, etcétera - en el que se advirtiese sobre aquellas exigencias de corrección que condicionan el buen ejercicio del urbanismo.

(Es evidente que la Administración podría, o no, tomar en consideración estas advertencias; pero en todo caso nuestra función técnica y obligación ciudadana estaria cumplida; y ya no seríamos responsables de

(2) Este tema lo vengo estudiando desde hace mucho tiempo y en particular con motivo del XII Congreso UIA. Ver "Metodologías», publicación del XII Congreso, "Conclusiones».

(3) La exactitud de esta afirmación puede comprobarse considerando el alcance mismo de los objetivos que el Consejo de Europa preconiza a través de la "Campaña para el Renacimiento de la Ciudad»: tales objetivos urbanísticos - los de «largo alcance» - están fuera del ámbito profesional del urbanista. 
las consecuencias futuras debidas a la falta de corrección).

b) Correcciones concretas que serian precisas en el ámbito de la Construcción, pero que habrian de ser fijadas, en normativa legal, por la Administración. (Procedería dirigirse a la Administración en tal sentido, apoyando la gestión con las actuaciones pertinentes).

c) Correcciones concretas que estén al alcance de la normativa corporativa profesional, que habrían de ser puestas en vigor directamente en el ámbito de las estructuras profesionales.

\subsection{Búsqueda de la máxima colaboración inter- disciplinaria}

Otro supuesto importante a considerar, que ejercería una gran influencia en la eficacia de los resultados, es el de promover la actuación con la máxima colaboración interdisciplinaria. Hemos diagnosticado la «incomunicación» que reina en el proceso de la Construcción; y dado que la remoción de este obstáculo afecta y favorece a todos los implicados -en particular a la Industria- es consecuente buscar la colaboración de todos (Tengo la experiencia directa y ampliamente confirmada de que los técnicos integrados en la Industria son mucho más receptivos a las exigencias de la "comunicación" en el proceso, que los técnicos que ejercen convencionalmente la profesión).

\subsection{Exigencias de redactar las diversas normati- vas coherentemente}

Crear "comunicación" en un ámbito supone dotar a tal ámbito de unidad de sentido, de coherencia; no podría, en modo alguno, darse coherencia si, por una parte "La Ley de la Edificación"; por otra parte las normas relativas a "Atribuciones" de cada uno de los profesionales específicos; por otra parte las normas relativas a "Responsabilidades"; por otra parte las normas relativas al Seguro de la Construcción; por otra parte, las normas relativas al "Control» ... etc. ... responden a criterios distintos o simplemente desconectados. El problema de la Construcción en un momento de transición cualitativa, como es el que vivimos, tiene que ser planteado y resuelto, en sus grandes líneas, en conjunto.

\subsection{El "hilo conductor" que nos proporciona el sentido de la corrección}

Es a partir del sentido de la actividad en el nivel actual, de donde se deduce el nuevo sentido que ha de ser imbuido en todos y cada uno de nuestros medios actuales - Metodologia, Atribuciones y Responsabilidades, Enseñanza, Industrialización, etcétera- de modo que todos queden orientados coherentemente entre sí y en concordancia con las nuevas exigencias (4).

\subsection{La labor práctica de corrección}

Constituye ésta, la labor propiamente dicha que corresponde al campo específico de la Construcción; y su desarrollo, aunque fuera esquemático, exigiria, por si solo, el espacio total de este artículo. No me cabe, por tanto, otra posibilidad que la simple referencia a sus líneas generales.

Consiste en el replanteamiento del proceso total de construcción que comprende programa y sus prioridades - con la implicación de terreno y entorno- proyecto y realización:

- El programa se plantea en el contexto de sus prioridades y de los supuestos y medios de información (Normativa, Bibliografia y otros medios de información).

- Las implicaciones de terreno y entorno dan lugar a exigencias y matizaciones que se identifican, a efectos prácticos, con necesidades de programa.

- Los "medios" - sentido de las soluciones, materiales, elementos, sistemas y tecnologiasse clasifican en el contexto del proceso natural del proyecto y realización, de acuerdo con sus adecuaciones y a lo largo del gradual escalonamiento de determinaciones que tal proceso implica. Naturalmente, esta labor exige un amplio y profundo trabajo en equipo y la participación - que es fundamental- de la Industria.

(La obra «Proyecto, realización y conservación de la Estructura" (1974) de J. Martínez Calzón y J. Martitegui, constituye un ejemplo, si bien parcial y limitado, de esta labor; y a pesar de contar con 900 páginas se refiere exclusivamente a la estructura en la Edificación).

Según se dirija el sentido de las determinaciones - de la investigación- se obtienen las correcciones sobre la orientación actual en los diversos campos del proceso, o en las funciones de los agentes y elementos que intervienen en el mismo:

- Así, si se profundiza en el campo de los supuestos y medios de información relativos a

(4) Véase, en la publicación «Metodologías» del XII Congreso UIA, "Conclusiones» y resultados relativos al análisis e interpretación de la «Encuesta sobre metodología del Proyecto de Arquitectura». (Estas "conclusiones" a pesar de estar expresadas en su propia publicación y ser fruto del Congreso, no han sido utilizadas, $y$, probablemente, ni siquiera entendidas, en el ámbito de la U.I.A.). 
programas, se obtienen las directrices de corrección relativas a la normativa - de programas - a la Bibliografia; y el sistema de clasificación al que debería responder la información.

- Si se profundiza en el campo de las funciones correspondientes a los diversos agentes implicados en el proceso - bien sea proyecto o realización- se obtienen las directrices relativas a Atribuciones y Responsabilidades, etc.

- Especialmente importante, por su trascendencia para la Industria, es la consideración de los materiales, elementos, sistemas y tecnologias contempladas en razón de sus adecuaciones y en orden a constituir una metodología de elección para el Proyectista y Realizador de obra; que conecta las prioridades del programa con las adecuaciones de los medios, etc.

En resumen, esta labor, desarrollada en sus diversas implicaciones y dirigida a comunicar el proceso de la Construcción hoy incomunicado, no sólo constituye un reto - técnicamente hablandopara los profesionales; sino que incidiría gradual, pero muy notablemente, en la economía nacional y en el prestigio de los profesionales mismos, dentro y fuera de nuestro país.

\section{NOTAS RELATIVAS A BIBLIOGRAFIA}

En un plazo corto, quien no desee quedarse fuera de tiempo y lugar y pretenda ponerse a la altura de las circunstancias, habrá de familiarizarse con una serie de disciplinas genéricas, no con el objetivo de hacerse experto o especialista en ellas, sino en orden a reconocer prácticamente, porque así lo exige nuestro momento de transición, la proposición de Descartes ("Discurso del Método»): ..."quién quiera buscar seriamente la verdad, no debe, pues, aplicarse a una sola ciencia, porque todas ellas se sostienen mutuamente y dependen unas de otras"...

A tal fin, entre las muchas que podrían enumerarse, son especialmente recomendables las siguientes obras:

Faustino Cordón. Todas sus obras, especialmente: «La alimentación, base de la biología evolucionista», Introducción general.

Jean Piaget. Todas sus obras; especialmente sus artículos sobre el significado de la Matemática y «El estructuralismo».

Arnold J. Toynbee. "Estudio de la Historia»; especialmente volúmenes I a V.

Teilhard de Chardin. Todas sus obras; especialmente: «El fenómeno humano".

Ludwig Von Bertalanffy. "Teoría general de los sistemas».

Werner Heisenberg. "Más allá de la Física».

C.F. Von Weizsäcker. «La física actual», «Historia de la Naturaleza», "La imagen física del mundo".

Erwin Schroedinger. "Ciencia y humanismo», "La mente y la materia». 